\title{
LA DEMOCRACIA EN MÉXICO: LA FALTA dE CULTURA POLÍtiCA AFECTA EL DESARROLLO DE LOS DERECHOS HUMANOS
}

\section{DEMOCRACY IN MEXICO: THE LACK OF POLITICAL CULTURE AFFECTS THE DEVELOPMENT OF HUMAN RIGHTS}

\section{Grisel Alejandra Correa Esquivel ${ }^{1}$}

\section{Resumen}

En este trabajo, nos proponemos analizar la necesidad de que tanto el Estado como los ciudadanos deben contribuir en el fortalecimiento y desarrollo de la democracia en México. Se analiza la democracia para un Estado constitucional, donde el centro es el respeto y protección de los derechos humanos, como base del desarrollo humano. Se postula la necesidad de la participación activa de la población, no sólo para ejercer control en el ejercicio del poder, sino para poner a prueba todo el sistema de gobierno nacional.

Palabras clave: Democracia, Participación ciudadana, Poder político, desarrollo humano, sistema de gobierno.

\begin{abstract}
In this paper, we analyze the need for both the State and citizens should contribute to the strengthening and development of democracy in Mexico. Democracy in a constitutional state has like central objective the respect and protection of human rights as the basis of human development. Add, the need for active participation of the population is postulated not only to establish control in the exercise of power, but also to test the whole system of national government.
\end{abstract}

Keywords: Democracy, citizen participation, political power, human development, government.

\footnotetext{
${ }^{1}$ Licenciada en Derecho por la Facultad de Derecho en la Universidad Autónoma del Estado de México.

E-mail: correa_14121987@hotmail.com
} 


\section{INTRODUCCIÓN}

México es un país con forma de Estado democrático, pluricultural en su conformación y multiétnico por su naturaleza. Resultado de grandes luchas sociales y de la adopción de regímenes jurídicos diversos hasta conformar una República representativa. Se integra en una federación, por el consenso de las entidades federativas que lo componen. Posee una sociedad multicultural, por el origen prehispánico de la raza mexicana, que lo lleva a poseer una identidad cultural propia, consiente de su realidad social, pero insensible al dolor ajeno. Pese a lo anterior, en estudios recientes, se dice que México es uno de los países más felices del mundo², a pesar de las enormes diferencias raciales, culturales y de las desigualdades sociales que en él se presentan.

México posee una riqueza natural excepcional, poco valorada por sus nacionales y ambicionada por países industrializados, carentes de espacios verdes para producir bienestar social y elevar los niveles de vida.

México, en aspectos relacionados con la educación, la salud, el empleo, las tasas de desarrollo y crecimiento, respeto a los derechos humanos, en las estadísticas mundiales de diversos organismos como la Organización de las Naciones Unidas, Organización de Estados Americanos, entre otros, obtiene los niveles bajos o intermedios, en comparación con naciones, -que aún sin ser potencias- mantienen las condiciones generales de bienestar en puntos positivos, mientras que México, ocupa las mejores posiciones en índices como obesidad, corrupción, contaminación, desigualdades económicas evidentes. Que sin duda generan una imagen internacional dañada y en ciertos aspectos, cómo un país que es incapaz de atender y dar soluciones de fondo a las distintas problemáticas sociales.

Es preciso señalar, que estas problemáticas tienen una solución. Sin embargo, requieren del trabajo decidido en conjunto con la sociedad y los órganos depositarios del poder.

En las siguientes líneas, abordaremos los elementos básicos que debe poseer la democracia en México, su relación con la cultura política del país, así como los derechos humanos. En este artículo hemos querido mostrar a la democracia como la base de un régimen político que de sustento a la cultura política de la sociedad como agente activo de ese régimen, y al mismo tiempo

2 En el World Happiness Report 2013, México ocupa el lugar número 16, por debajo de Canadá, Australia, Austria, Alemania, Suecia, Suiza, entre otros, e incluso de otros países de Latinoamérica, como Costa Rica. El reporte de referencia puede ser consultado en:

http://unsdsn.org/files/2013/09/WorldHappinessReport2013_online.pdf

Revista de Direito da Cidade, vol.07, no01. ISSN 2317-7721 p.275-302 276 
pueda la democracia garantizar el reconocimiento, respeto y ejercicio de los derechos humanos. Pretendemos evidenciar como actores políticos y sociales, a los integrantes del gobierno y a los habitantes del país, cuya acción conjunta permita el control en el ejercicio del poder, concientizar a los habitantes como accionantes y destinatarios del sistema político, incluso antes y sin formar parte de los órganos de gobierno.

\section{DEMOCRACIA. PERSPECTIVAS TEÓRICAS}

Por muchos años, un régimen democrático ha sido ansiado por los países, como una garantía para el desarrollo de los seres humanos, para el control del poder y el respeto a la Constitución de cualquier país.

El pasó por la historia de cada país, a través de regímenes autoritarios, absolutistas, totalitarios, han motivado el desarrollo de regímenes donde el consenso de las partes y el respeto por los derechos humanos sea estandarte que guíe el ejercicio del poder. Alrededor del mundo, estos movimientos en la consecución de la democracia, se ven de forma eficiente en el continente Europeo; no obstante, América Latina permanece en constante lucha para lograr elecciones limpias, como un elemento de la democracia de calidad.

El autor Jorge Carpizo, al hablar de democracia nos señala lo siguiente: "mientras los países de Europa occidental han alcanzado, después de la Segunda Guerra Mundial, sistemas democráticos con estabilidad y un desarrollo socioeconómico impresionante, los países de América Latina han sufrido múltiples fracasos democráticos, debido a golpes de Estado, gobiernos autocráticos, militares y dictatoriales, aunados a graves problemas sociales y económicos"3.

Donde podemos observar, que los niveles de democracia han sido profundamente arraigados en la parte del continente europeo, en atención a las condiciones demográficas y socioculturales. Sin embargo, en América Latina, el proceso de democratización ha sido resultado de constantes confrontaciones sociales por el poder y el respeto de los derechos humanos. Como muchas otras instituciones, no podemos adoptarlas en América Latina por simple similitud, sino se debe atender a formas de gobierno siempre adecuadas a las características de cada país.

\footnotetext{
${ }^{3}$ Aproximadamente el $43 \%$ de los habitantes de la región viven en la pobreza, son los países con los niveles de desigualdad social más agudos en el mundo, la concentración de la riqueza es indignante y los rezagos en los sistemas de salud, educación, vivienda y trabajo son inmensos. En Carpizo, Jorge, "Concepto de democracia y sistema de gobierno en América Latina", Boletín Mexicano de Derecho Comparado, México, Universidad Nacional Autónoma de México, 2007, número 119, p. 95
}

Revista de Direito da Cidade, vol.07, no01. ISSN 2317-7721 p.275-302 277 
El autor en comento señala que, "la democracia de nuestros días nació en Nueva Zelandia en 1893, al concederse derecho de voto a las mujeres y a la minoría maorí. No obstante, no se reconoció a la mujer el derecho de ser electa, sino hasta 1902"4 . Sin embargo, no podemos centrar a la democracia únicamente en el voto y en reconocimiento de ese derecho. La democracia es más que simples elecciones y emisión del voto.

Al respecto podemos citar la opinión de Heraldo Muñoz, Subsecretario General de la ONU y Director Regional para América Latina y el Caribe del Programa de Naciones Unidas para el Desarrollo, quien nos dice que, "La democracia no sólo se caracteriza por el insustituible acto electoral, sino también por la forma en que se ejerce el poder y se logran mínimos efectivos de ciudadanía".

Aun así, no sólo se trata del ejercicio del poder, sino del control en el ejercicio de ese poder, y además no se refiere únicamente de lograr los mínimos efectivos de la ciudadanía, pues es una calidad que se adquiere hasta cubrir ciertos requisitos -entre ellos, la mayoría de edad-, y surge la pregunta, ¿Qué ofrece la democracia para los no ciudadanos? De este modo, la democracia debe proveer a todos los habitantes de un país, las condiciones que les permitan una constante mejora en el nivel de vida que poseen.

Por ello afirmamos, que la democracia, no es solo elecciones y derechos políticos de los ciudadanos. Situación que iremos desglosando a lo largo de este trabajo.

Antes de referirnos a aquello que corresponde a la democracia y que no forma de ella, podemos empezar por conceptuarla. Así, para Jorge Carpizo, la democracia es el "sistema en el cual los gobernantes son electos periódicamente por los electores; el poder se encuentra distribuido entre varios órganos con competencias propias y con equilibrios y controles entre ellos, así como responsabilidades señaladas en la Constitución con el objeto de asegurar los derechos fundamentales que la propia Constitución reconoce directa o indirectamente" ${ }^{\prime 5}$.

Esta definición, ya muestra algunos elementos sobre el sistema que implica la democracia; en primer término, tenemos el ejercicio y control del poder -a cargo de gobernantes elegidos para tal efecto-, mediante un régimen de responsabilidades establecidas en la Constitución. Este sistema democrático, asegura, en palabras de Carpizo, los derechos fundamentales reconocidos directa o

\footnotetext{
${ }^{4}$ Ibídem., p. 97

${ }^{5}$ Ibídem., p. 100
}

Revista de Direito da Cidade, vol.07, no01. ISSN 2317-7721 p.275-302 278 
indirectamente. No obstante, la democracia debe ir más allá del reconocimiento de los derechos fundamentales, debe garantizar la esfera humana de los habitantes de cualquier país.

Es conveniente revisar la opinión de O’ Donnell, quien al respecto nos dice, “la democracia política no es el resultado de algún tipo de consenso, o elección individual, o contrato social, o proceso deliberativo. Es el resultado de una apuesta institucionalizada. El sistema legal asigna a cada individuo múltiples derechos y obligaciones" ${ }^{\prime 6}$.

El autor en cita, explica que se trata de una apuesta institucional, cómo una forma de imposición a los sujetos, con independencia de sus preferencias, pues "cada ego debe aceptarla incluso si cree que permitir a ciertos individuos votar o ser electos es inadecuado ${ }^{7 "}$. No se trata de un régimen establecido por el total de una población, sino es un sistema impuesto por aquellos que se encuentran en el ejercicio del poder, en ese entendido, aun cuando se trata de una imposición, no debe permitir la trasgresión de los derechos humanos de los habitantes, y en esencia estaría lejos de ser una forma democrática de gobierno. Ahora bien, puede encontrarse legitimación en esta forma de imposición, si quien los ha elegido, lo hace con base en un sistema equilibrado.

Estos derechos fundamentales y humanos, son conditio sine qua non para la existencia de la democracia, pues son la base de los diversos procesos que la integran. En este sentido, un régimen democrático presupone: "a. un estado territorialmente basado que delimita a quienes son considerados ciudadanos/as políticos/as; y b. un sistema legal de ese mismo estado que, dentro de su territorio, asigna la ciudadanía política sobre bases (limitadamente) universalistas" ${ }^{8}$.

El autor continua diciendo que, "un régimen democrático consiste en algunas libertades 'políticas' (limitadamente) universalistas. Estas libertades deben ser listadas porque son importantes per se y porque son condiciones necesarias para la existencia de las elecciones limpias e institucionalizadas, y por lo tanto para la continua efectividad de la apuesta democrática" ${ }^{9}$.

De acuerdo con O’Donnell, Estado y ciudadano tienen una relación en función de la democracia, pues el mismo Estado califica a quienes poseen dicha calidad mediante el sistema

\footnotetext{
${ }^{6}$ Los individuos no los eligen; desde su nacimiento se encuentran inmersos en una compleja red social; esta red social incluye derechos y deberes establecidos y respaldados por el sistema legal del estado en el que viven. En O' Donnell, Guillermo, "Democracia, Desarrollo humano y Derechos humanos", Democracia, desarrollo humano y ciudadanía. Reflexiones sobre la calidad de la democracia en América Latina, Argentina, Homo Sapiens ediciones, 2003, p. 44

7 Ídem

${ }^{8}$ Ibídem., p. 51

${ }^{9}$ Ibídem., p. 50
}

Revista de Direito da Cidade, vol.07, no01. ISSN 2317-7721 p.275-302 279 
normativo, tratando igual a los que están en situación de igualdad. Esta relación política genera derechos y obligaciones par ambos sectores de la población.

Para el Programa de las Naciones Unidas para el Desarrollo, la función de la democracia "es redistribuir el poder para garantizar a los individuos el ejercicio de sus derechos. Pero, para lograr organizar el poder en la sociedad, la democracia a su vez precisa poder" ${ }^{10}$. La democracia, tiene una doble lucha, pues requiere del poder para organizar a la sociedad y consagrar los derechos de la sociedad misma, y a la vez, debe controlar el ejercicio del poder, a fin de encontrar un equilibrio donde el poder sea la guía en el desarrollo del gobierno, sin vulnerar los derechos de los habitantes de cualquier Estado.

Con lo dicho en el párrafo anterior, surge un término que nos ayuda a entender las funciones de la democracia, y es la gobernabilidad. Y por este término entendemos que, "la gobernabilidad comprende los mecanismos, procesos e instituciones que determinan cómo se ejerce el poder, cómo se toman las decisiones sobre temas de inquietud pública y cómo los ciudadanos articulan sus intereses, ejercitan sus derechos legales, cumplen sus obligaciones y median sus diferencias"11. Por ello, la democracia debe complementarse con otras herramientas que le permitan cumplir con sus finalidades esenciales.

Para entender cuáles son las finalidades esenciales de la democracia, se tienen diversas caras de una misma moneda; es decir, la democracia adquiere algunas connotaciones en virtud de un elemento que la identifica. Con ello, hablamos de la democracia de acuerdo a un lapso enfatizado y los elementos considerados. De ahí que, tenemos a la democracia electoral, la democracia sustantiva y la democracia de la ciudadanía.

La democracia electoral, "se ciñe a los periodos electorales y los elementos políticos (libertades civiles o personales, derechos políticos y estado de derecho) ${ }^{12 \prime \prime}$. Por su parte, la

\footnotetext{
10 Programa de las Naciones Unidas para el Desarrollo, Nuestra democracia, PNUD, México, FCE, PNUD, OEA, 2010, p. 29

11 EI PNUD considera que la gobernabilidad democrática es fundamental para generar cambios positivos en las naciones y en las comunidades. Ayuda a los gobiernos a crear instituciones y métodos electorales, judiciales y de seguridad, responsables e independientes, que promuevan elecciones justas e inclusivas y un estado de derecho, centrándose especialmente en la mujer y en los grupos marginados. Programa de las Naciones Unidas para el Desarrollo, Informe Anual 2012, Desarrollo centrado en las personas, PNUD, 2012, p. 12

12 Lizcano Fernández, Francisco, et. al., "Conceptos de democracia y calidad de la democracia”, en Lizcano Fernández, Francisco y Retana Ramírez, Ruperto (coords.), Estado de México y democracia en los albores del siglo XXI, México, 2010, p. 9
}

Revista de Direito da Cidade, vol.07, no01. ISSN 2317-7721 p.275-302 280 
democracia sustantiva, toma en consideración los elementos políticos anteriores, en los periodos donde las elecciones no están presentes. La democracia de la ciudadanía, une la finalidad de la democracia electoral y sustantiva, sumando a lo político, elementos socioeconómicos.

Para precisar un poco más sobre estas concepciones de la democracia, se percibe a la democracia electoral, "como una determinada forma de acceder al poder"13. Dentro de esta acepción de la democracia, se refiere a un "procedimiento electoral para que los ciudadanos elijan de entre las élites que disputan el poder a la que habrá de asumirlo en tanto obtenga el mayor número de votos, en condiciones tales que existan libertades fundamentales como la de prensa"14.

Vista de esta forma, la democracia, constituye un medio para acceder al poder, un instrumento para la garantía de las libertades fundamentales de los individuos, un proceso para la elección de los gobernantes y representantes que han de asumir el ejercicio del poder. Al respecto Covián Andrade, nos dice que "si la democracia inicia y termina en la etapa del origen del poder, entonces carece de sentido plantearse la pregunta sobre el grado de democraticidad de un sistema político en las etapas relativas a su ejercicio y a sus fines" ${ }^{15}$.

Resulta conveniente traer al presente, los aspectos que O' Donnell considera deben ser tomados en cuenta para estar frente a un verdadero régimen democrático, desde la perspectiva del ciudadano:

1. Cuántos tienen una preferencia clara y presumiblemente estable por un régimen democrático respecto de cualquier otro;

2. Cuántos aceptan que la población territorialmente limitada por el estado en el que viven es la unidad que determina la definición del electorado;

3. Cuán informados están acerca de los partidos, candidatos y temas de cada elección;

4. Cuán interesados están acerca de estos temas;

5. Cuánto y de qué manera participan en actividades políticas, especialmente las relacionadas con las elecciones;

6. Si y cuánto usan las oportunidades existentes para expresar opiniones sobre la discusión, decisión o implementación de políticas públicas.

\footnotetext{
13 Ibídem., p. 13

14 Ibídem., pp. 15-16

${ }^{15}$ Covián Andrade, Miguel, "Retos del sistema electoral y de la democracia mexicana en el siglo XXI", México, Cámara de Diputados, disponible en: www.diputados.gob.mx/documentos/consejeros_2013/ensayo/30.pdf, consultado: 18/02/2014g
}

Revista de Direito da Cidade, vol.07, noㅣ. ISSN 2317-7721 p.275-302 281 
En este sentido, Norris afirma lo siguiente, "todos los teóricos están de acuerdo en que la participación es uno (pero sólo uno) de los indicadores de la solidez de cualquier democracia"16. Es por ello, la importancia de determinar la forma en que cada ciudadano se ocupa y preocupa por la vida política de su país. Es decir, que tan dispuesto está a ser informado de la forma en cómo los partidos políticos acceden al poder, lo beneficios ofrecidos y la facilidad para poder participar de manera activa y pasiva en los procesos políticos de integración del gobierno en el ejercicio del poder $^{17}$.

O’Donnell, respecto del sistema electoral como parte del régimen democrático, considera lo siguiente:

${ }^{16}$ Norris, Pipa, "La participación ciudadana: México desde una perspectiva comparativa", Deconstruyendo la ciudadanía: Avances y retos en el desarrollo de la cultura democrática en México, México, Instituto Federal Electoral, 2002, p. 3

17 De acuerdo con Norris, existen dos corrientes de pensamiento para explicar la forma de participación ciudadana en la democracia. "Por un lado está la visión del deterioro, que sugiere que desde fines del siglo XX muchas sociedades postindustriales han experimentado tendencias seculares continuas de distanciamiento de los ciudadanos de los canales tradicionales de participación política. Entre los síntomas de este mal se incluyen la caída en los niveles de participación en las elecciones, la intensificación de los sentimientos antipartidistas y la decadencia de las organizaciones civiles. Se ha expresado preocupación respecto a estas cuestiones en discursos públicos, columnas de opinión y estudios académicos. Estas voces se escuchan con mayor frecuencia en los Estados Unidos, pero en muchas otras democracias se escuchan ecos similares. La visión del deterioro hace hincapié en que esta pauta es particularmente evidente en muchas sociedades postindustriales prósperas y en las democracias más añejas, aunque pueden encontrarse síntomas semejantes en las democracias en consolidación y en los países en desarrollo. Puesto que el contagio aqueja a muchas sociedades, las explicaciones se buscan en causas generales y no en las experiencias particulares de cada nación. El punto de vista estándar señala una letanía conocida de males civiles que se considera que han minado los canales democráticos que tradicionalmente vinculan a los ciudadanos con el estado. Las elecciones son la forma más común para que las personas expresen sus preferencias políticas, y las urnas semivacías se consideran el síntoma más común de la mala salud de las democracias". La otra perspectiva sugiere, más que erosionarse, la naturaleza del activismo político se ha reinventado en las últimas décadas a través de la diversificación de las agencias (las organizaciones colectivas que estructuran las actividades políticas); los repertorios (las acciones que se emplean comúnmente para la expresión política); y los objetivos (los actores políticos en los que los participantes pretenden influir). El repentino auge de la política de protesta, los nuevos movimientos sociales y el activismo por Internet pueden interpretarse como ejemplos de distintos aspectos de este fenómeno. Si bien las oportunidades de expresión y movilización política se han fragmentado y multiplicado con los años, como un río crecido que se ve alimentado por sus distintas afluentes, la participación democrática puede haberse adaptado y evolucionado de acuerdo con la nueva estructura de oportunidades en lugar de simplemente atrofiarse. ¿Por qué habríamos de esperar que las formas de activismo político se modifiquen con el tiempo? La razón más plausible proviene de las teorías de la modernización que sugieren que el factor que impulsa estos cambios es el proceso a largo plazo del desarrollo humano, particularmente el aumento en los niveles de alfabetización, educación y riqueza. Norris, op. cit., p. 4-5

Revista de Direito da Cidade, vol.07, no01. ISSN 2317-7721 p.275-302 282 
1. Si existe una comisión o tribunal electoral independientemente, imparcial y adecuadamente investido de autoridad y recursos como para garantizar la limpieza de las elecciones, tanto a nivel nacional como internacional;

2. Si el sistema electoral no sobrerrepresenta ciertos distritos o ciertos tipos de electores, $y$, ese es el caso, en que medida;

3. Si compensa significativamente las desventajas que ciertos partidos pueden sufrir por el hecho de no ser apoyados por grupos económicamente poderosos;

4. Si existen reglas claras y aplicables para la publicidad de las contribuciones que los partidos políticos reciben para las campañas electorales y para su funcionamiento;

5. Si no pone altas barreras a la creación y desempeño de los partidos políticos, con excepción de los que abogan por el uso de medios violentos para la competición política y/o para acceder a posiciones gubernamentales;

6. Si no existen complicados requisitos para el registro de los votantes, especialmente los que pueden ser difíciles de satisfacer por individuos pobres y/o discriminados/as;

7. Si los/las ciudadanos/as son libres de afiliarse a un partido, de tratar de ser escogidos/as como candidatos/as del mismo y, si lo son, para presentarse a elecciones;

8. Si todos los partidos y candidatos/as son tratados respetuosa e imparcialmente por las autoridades gubernamentales;

9. Si las elecciones nacionales son realizadas con suficiente frecuencia como para reflejar importantes cambios en la opinión pública, y si hay mecanismos legales que permiten a los ciudadanos, con debidos recaudos para evitar decisiones minoritarias y/o apresuradas, remover a los funcionarios electos, si lo consideran necesario, entre elecciones ${ }^{18}$.

En este sentido, Covián afirma que "de nada sirve que se cumplan las leyes electorales si no se logra que la integración de los órganos de representación política tenga correspondencia con la expresión de voluntad de los ciudadanos. Las normas electorales son sólo un medio, indispensable sin duda, para hacer posible la democracia electoral, cuyo fundamento es incuestionablemente, la legitimidad del origen del poder"19.

\footnotetext{
${ }^{18}$ O’ Donnell, Guillermo, op. cit., pp. 53-54

${ }^{19}$ Covián, op. cit.
} 
Podemos afirmar, con base en lo anterior, que los ciudadanos y el sistema electoral, de forma separada o individual no pueden conformar una democracia, entendida en forma restringida, ni mucho menos una democracia de rasgo social.

De este modo, O’ Donnell, señala los parámetros que deben tomarse en cuenta, para calificar de democrático a cualquier régimen de gobierno.

Así, la democracia es una forma de organización del poder en la sociedad con el objetivo de ampliar la ciudadanía, evitar o limitar la dominación de individuos o grupos que impidan este objetivo y lograr la perdurabilidad de la organización democrática. Regula las relaciones entre individuos, organizaciones y Estado de acuerdo con normas emanadas de la voluntad popular y procedimientos democráticos. En el ejercicio de ese poder el Estado es una pieza vital. Una democracia con un Estado anacrónico, ineficiente e ineficaz no puede resolver las carencias que la debilitan ${ }^{20}$

Estado, sociedad y democracia deben formar una simbiosis que facilite la coexistencia de estos elementos, y aminorar cualquier agente que cause desequilibrio. Derivado de la opinión de estos autores, podemos señalar que la organización democrática del poder posee, en este sentido, tres rasgos que se vinculan de manera estrecha con su legitimidad:

1. Su origen en la soberanía popular expresada mediante procesos electorales periódicos, libres y transparentes. La democracia parte de la idea de que el poder descansa en el pueblo y que su ejercicio solo es delegado. Lo que implica un mandato, capacidad para ser controlado y la posibilidad de alternancia y periodicidad de los mandatos;

2. Su ejercicio, organizado a través de las instituciones republicanas de gobierno y normado en el Estado democrático de derecho, se refiere a como se toman las decisiones para formular las políticas públicas y las normas;

3. Su finalidad es garantizar, materializar y extender los derechos ciudadanos en sus tres esferas: política, civil y social, a partir de la clásica definición de T. H. Marshall. La ampliación de los derechos es entendida como su realización efectiva ${ }^{21}$.

Estos tres rasgos, nos refieren a las democracias señaladas anteriormente de tipo electoral, sustantiva y de la ciudadanía. Una democracia electoral refiere directamente a la alternancia en el ejercicio del poder y la periodicidad de esa alternancia, únicamente con los órganos integrados

\footnotetext{
20 Programa de las Naciones Unidas para el Desarrollo, Nuestra democracia, op. cit., p. 35 21 Ídem.
} 
como consecuencia de una elección. Por su parte, la democracia sustantiva "se relaciona con los procesos por medio de los cuales los ciudadanos comunes ejercen un grado relativo de control sobre los dirigentes" ${ }^{22}$.Dentro de la concepción sustantiva de la democracia, los ciudadanos deben estar en posibilidad de ejercer tres derechos o prerrogativas, en idéntico grado de igualdad de oportunidades para:

1. Formular sus preferencias;

2. Manifestar públicamente dichas preferencias entre sus partidarios y ante el gobierno, individual y colectivamente;

3. Recibir por parte del gobierno igualdad de trato: es decir, éste no debe hacer discriminación alguna por causa del contenido o del origen de tales preferencias en la ponderación de las preferencias $^{23}$.

Dahl considera que para permitir la realización de estas tres condiciones será necesario cumplir con otros requisitos. Para él, y para los países, los medios para garantizar estas tres condiciones se constituyen a través de su reconocimiento como derechos fundamentales o humanos, según el sistema jurídico de que se trata, a saber estos son:

1. Libertad de asociación;

2. Libertad de expresión;

3. Libertad de voto;

4. Elegibilidad para el servicio público;

5. Libertad para que los líderes políticos compitan en busca de apoyo;

6. Diversidad de fuentes de información;

7. Elecciones libres e imparciales;

8. Instituciones que garanticen que la política del gobierno dependa de los votos y demás formas de expresar las preferencias ${ }^{24}$.

En la concepción de Dahl, la democracia se aleja de poner en primer término a las autoridades encargadas del ejercicio del poder y que derivan de los procesos electorales, por lo que pone en los primeros lugares de la lista a los derechos humanos que han sido reconocidos por nuestro país en la Constitución Política de los Estados Unidos Mexicanos, lo que los convierte en

\footnotetext{
22 Lizcano Fernández, Francisco, et. al., op. cit., p. 22

${ }^{23}$ Ibídem., p. 24

24 Ídem.
}

Revista de Direito da Cidade, vol.07, no01. ISSN 2317-7721 p.275-302 285 
derechos fundamentales gozando, al menos en la letra de la ley, de garantías procesales constitucionales para su respeto y protección. Sin embargo, Dahl sigue centrándose en aspectos políticos y deja fuera de la concepción de democracia aspectos relacionados con lo humano o esencial del hombre.

Al respecto, Dworkin afirma que "la democracia puede gozar de una buena salud aun careciendo de un debate político serio si existe un consenso amplio acerca de lo que hay que hacer. Puede ser una democracia saludable incluso sin existir consenso si posee una cultura del debate. Pero no puede mantener la buena salud si padece divisiones profundas y encarnizadas y carece de un debate real, porque entonces se convierte en una mera tiranía del número"25.

En consonancia con lo señalado por Dworkin, la democracia no es necesariamente elecciones y procesos de representación. La democracia tiene que ver con la cultura del diálogo y del debate, para convertirse en una forma de gobierno puro, tal como lo denominó Aristóteles, en donde la participación no sólo del ciudadano sino de cualquier integrante de la población de un Estado, contribuya al diseño e implementación de políticas públicas encaminadas al bien común y al progreso social.

Parte importante de la concepción humana de la democracia, deriva de la Resolución de la Comisión de Derechos Humanos número 1999/57, en donde se refiere a la Promoción del derecho a la democracia. En dicha resolución, se parte de la idea de que todos los pueblos tienen derecho a la libre determinación, en virtud del cual deciden libremente su condición política y persiguen en libertad su desarrollo económico, social y cultural. Además, considera que la democracia se basa en la voluntad libremente expresada de los pueblos de determinar sus propios sistemas políticos, económicos, sociales y culturales y en su participación plena en todos los aspectos de su vida; por lo que señala tres afirmaciones:

1. Afirma que la democracia promueve la plena realización de todos los derechos humanos, y viceversa;

2. Afirma también que entre los derechos a una gestión pública democrática figuran los siguientes:

a) El derecho a la libertad de opinión y de expresión, de pensamiento, de conciencia y de religión, de asociación y de reunión pacíficas;

\footnotetext{
25 Dworkin, Ronald, La democracia posible. Principios para un nuevo debate político, España, Paidós, 2008, p. 21
}

Revista de Direito da Cidade, vol.07, no01. ISSN 2317-7721 p.275-302 286 
b) El derecho a la libertad de investigar y de recibir y difundir informaciones e ideas por cualquier medio de expresión;

c) El imperio de la ley, incluida la protección jurídica de los derechos, intereses y seguridad personal de los ciudadanos y la equidad en la administración de la justicia, así como la independencia del poder judicial;

d) El derecho al sufragio universal e igual, así como a procedimientos libres de votación y a elecciones periódicas libres;

e) El derecho a la participación política, incluida la igualdad de oportunidades de todos los ciudadanos para presentarse como candidatos;

f) Instituciones de gobierno transparentes y responsables;

g) El derecho de los ciudadanos a elegir su sistema de gobierno por medios constitucionales u otros medios democráticos;

h) El derecho de acceso, en condiciones de igualdad, a la función pública en el propio país;

3. Observa que la realización de todos los derechos humanos -civiles, culturales, económicos, políticos y sociales, incluido el derecho al desarrollo- es indispensable para la dignidad humana y el pleno desarrollo del potencial del ser humano y también forma parte integrante de toda sociedad democrática ${ }^{26}$.

Con esta resolución, la Organización de las Naciones Unidas pone de manifiesto la importancia de tomar en consideración para una comunidad democrática, la realización de los derechos humanos, incluso el derecho al desarrollo para garantizar el respeto a la dignidad humana y potenciar al ser humano, como parte integrante de cualquier sociedad democrática.

Retomando las formas de democracia, es oportuno hablar de la democracia de la ciudadanía, en donde se destacan los derechos que estos individuos con calidad de ciudadanos poseen. Por ciudadanía se entiende como "un tipo de igualdad básica asociada al concepto de pertenencia a una comunidad, que en términos modernos es equivalente a los derechos y obligaciones de los que todos los individuos están dotados en virtud de su pertenencia a un Estado nacional"27.

\footnotetext{
${ }^{26}$ Organización de las Naciones Unidas, "Promoción del derecho a la democracia", Resolución de la Comisión de Derechos Humanos 1999/57, 1999, disponible en: www.unhchr.ch/huridocda/huridoca.nsf/8ce8951852ee031cc1256991003793c3/d5d1445feb8c7e3c8025676 e003b4495?OpenDocument

${ }^{27}$ Lizcano Fernández, Francisco, et. al., op. cit., p. 28
}

Revista de Direito da Cidade, vol.07, no01. ISSN 2317-7721 p.275-302 287 
A los derechos a los que se refiere esta definición, son los derechos civiles, políticos y sociales de los que cada país reconoce a sus habitantes. Esta ciudadanía civil, de acuerdo con Caputo, tiene dos dimensiones: la de necesidades básicas: salud y educación, y la segunda: la de integración social: empleo, pobreza y desigualdad ${ }^{28}$. De la dimensión relacionada con las necesidades básicas nos ocuparemos en este trabajo.

Es importante recordar la opinión de O’Donnell, quién nos señala que "bajo un régimen democrático, los derechos a la participación política, así como los de expresión, asociación, movimiento y semejantes, deben ser respetados en virtud de la propia definición de ese régimen si no lo son, ese régimen deja de ser democrático" 29 .

La democracia es más que elecciones, partidos políticos, representación del poder. La democracia, como lo señala el artículo tercero de la Constitución Política de los Estados Unidos Mexicanos, debe ser entendida "no solamente como una estructura jurídica y un régimen político, sino como un sistema de vida fundado en el constante mejoramiento económico, social y cultural del pueblo". En otras palabras, es un sistema que por su propia naturaleza debe generar bienestar en la población, pues atiende de manera efectiva y con calidad las necesidades de la población.

Es oportuno señalar, que más que vertientes de la democracia, son momentos de la democracia, es decir, el acceso al poder -propio de la democracia electoral-, a través de partidos o asociaciones políticas y procesos electorales, es un primer momento para iniciar en el ejercicio de éste; por su parte, la democracia sustantiva y la de la ciudadanía, conforman la parte social de la democracia, pues implica participación activa y la posibilidad de mantener un control sobre los órganos depositarios del poder. Es decir, partimos de la idea de que la democracia se conforma con base en la triada habitante-gobernante-habitante. De modo tal, que el trinomio no puede disolverse puesto que no hay democracia sin una población a quien dirigir las acciones de gobierno, y el gobierno deja de funcionar en beneficio de la sociedad, sí está carece de interés en el funcionamiento y estructura del ejercicio del poder.

\footnotetext{
${ }^{28}$ Ibídem, p. 30

${ }^{29}$ O’ Donnell, Guillermo, op. cit., p. 123
}

Revista de Direito da Cidade, vol.07, no01. ISSN 2317-7721 p.275-302 288 


\section{Cultura. Cultura política y cultura democrática}

La participación de la ciudadanía en la conformación de la democracia requiere de ciertos valores, principios y un nivel de conciencia sobre el papel que desempeña en un régimen de gobierno de esta naturaleza.

Antes de identificar a la cultura de tipo político o democrático, se hace necesario entender el término cultura. De acuerdo con la Organización de las Naciones Unidas para la Educación, la Ciencia y la Cultura (UNESCO), la cultura actualmente refiere al conjunto de los rasgos distintivos, espirituales y materiales, intelectuales y afectivos que caracterizan a una sociedad o un grupo social. Ella engloba, además de las artes y las letras, los modos de vida, los derechos fundamentales al ser humano, los sistemas de valores, las tradiciones y las creencias y que la cultura da al hombre la capacidad de reflexionar sobre sí mismo. Es ella la que hace de nosotros seres específicamente humanos, racionales, críticos y éticamente comprometidos. A través de ella discernimos los valores y efectuamos opciones. A través de ella el hombre se expresa, toma conciencia de sí mismo, se reconoce como un proyecto inacabado, pone en cuestión sus propias realizaciones, busca incansablemente nuevas significaciones, y crea obras que lo trascienden ${ }^{30}$.

La cultura se convierte en el cúmulo de saberes, hechos y actos del ser humano, que lo caracterizan e identifican y le dan pertenencia a una comunidad o población. La cultura en el individuo, permite la creación y el desarrollo de formas de expresión, como lo son el lenguaje o las artes, conformación de sistemas de valores, formación de un pensamiento crítico, constructivo. Es decir, la cultura, forma parte del rasgo esencial y distintivo del género humano.

Retomando la idea de Aristóteles, de que el hombre es un zoon politikon, es decir un "animal político", una persona que esta en constante interacción con sus semejantes, mediante relaciones familiares, laborales, vecinales, entre otras. Este hombre político, debe ser sensible con sus semejantes y responsable de cumplir con sus derechos y obligaciones.

Cada grupo de individuos requiere de sentirse identificado para conformar una pertenencia al cúmulo de personas de que se trate, ya sea como familia, como parte de un equipo de trabajo, de algún club social, organización social o civil, de un Estado, un municipio, una delegación, como formas de delimitación territorial. Pertenecer a cualquiera de estos grupos, implica cuestiones

30 Organización de las Naciones Unidas para la Educación, la Ciencia y la Cultura (UNESCO), web site: http://www.unesco.org/new/es/mexico/work-areas/culture/

Revista de Direito da Cidade, vol.07, no01. ISSN 2317-7721 p.275-302 289 
relacionadas con liderazgo o conducción de grupos. Ello, invita a los integrantes de cualquier forma de organización se ocupen de elegir personas y sistemas que aseguren de forma equilibrada los procesos para la elección de representantes o de sus dirigentes.

De este modo, la cultura comienza a relacionarse con el tema de la política. Es así que, la cultura adquiere dimensiones políticas; pues, a través de la cultura se pueden manifestar diversas ideologías y formas de pensar, comprende sus diversas formas y medios de asignar el poder y la toma de decisiones. En este sentido, la cultura adquiere dimensiones políticas, al encontrar formas de asignación y aceptación del poder.

En opinión de Peschard, "la cultura política de una nación es la distribución particular de patrones de orientación sicológica hacia un conjunto específico de objetos sociales los propiamente políticos entre los miembros de dicha nación. Es el sistema político internalizado en creencias, concepciones, sentimientos y evaluaciones por una población, o por la mayoría de ella" ${ }^{31}$.

Estos patrones de orientación psicológica, se enfocan en las formas de organizar el poder, principalmente el poder político de un país. Peschard, continúa señalando que en el centro del término cultura política se encuentra un "conjunto de relaciones de dominación y de sujeción, esto es, las relaciones de poder y de autoridad que son los ejes alrededor de los cuales se estructura la vida política"32. Sintetiza este apartado al señalar que la cultura política conforma un "imaginario colectivo construido en torno a los asuntos del poder, la influencia, la autoridad, y su contraparte, la sujeción, el sometimiento, la obediencia y, por supuesto, la resistencia y la rebelión"33.

La vida política de un país, se determina por las relaciones que se dan torno al término poder y a las diferentes formas de ejercerlo. En su concepción más simple, "el origen mismo de la voz poder orilla a la adhesión o al rechazo. La raíz indoeuropea 'poti', poderoso, amo, marcó el sino del concepto. En Grecia, el amo doméstico era el 'dems-pot' como 'posse', el vulgar le reintegró su contundencia 'potere'"'34.

En una perspectiva de dominación, tenemos la clásica concepción de Weber acerca del poder, este autor entiende por poder "la posibilidad de imponer la propia voluntad sobre la

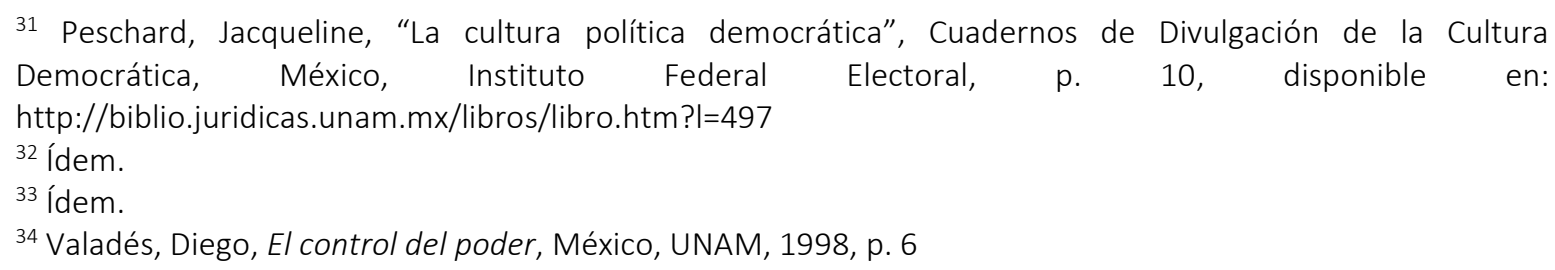


conducta ajena" ${ }^{35}$. Es precisamente está imposición la que diferencia el poder de la autoridad. Pues la autoridad se basa en la legitimación del sujeto para desprender la capacidad de ser obedecido, es decir no hay imposición de conductas, sino la modificación de la conducta se logra por medio del convencimiento y no de la fuerza.

De aquí que, esa diferencia permita el surgimiento del poder político de un Estado, pues mediante el ejercicio del poder en el marco de los ordenamientos jurídicos, se permite la elección o designación de autoridades estatales, y es mediante normas que los sujetos electos logran legitimación para el ejercicio del poder público del Estado. Es aquí donde el concepto de democracia de O’Donnell adquiere vigencia, pues poder y democracia se une, aún cuando la segunda presuponga al primero.

Por lo que en momentos, se tiene la percepción que el total del pueblo no ha legitimado a los sujetos que ejercen el poder de forma directa. Sin embargo, de forma indirecta, el pueblo legítima ese poder y esa autoridad, por el ya conocido pacto o contrato social, que en su momento propusiera Rousseau ${ }^{36}$, como teoría para el surgimiento del Estado.

Poder, autoridad y población, forman una relación indisoluble, pues ya sea mediante el ejercicio del poder o de la autoridad, el pueblo como detentador del poder, tiene la facultad de elegir quien asuma ese poder en su representación, además de que quién ejerce lo ejerce proviene del mismo pueblo, de ahí que podríamos derivar una doble legitimación, como detentador y como operador del poder.

Con lo señalado en líneas precedentes, la cultura le permite al individuo expresar su ideología y sus propias concepciones respecto de cualquier objeto de la realidad. La política atiende a todo lo relacionado con el ejercicio del poder, con las funciones de gobierno de un país. Estos dos términos se relacionan al integrar una sola concepción de cultura política.

El término cultura política, refiere las diversas formas que una población tiene, de concebir las relaciones entre el ejercicio del poder y la obediencia a éste, y los fenómenos conductuales, que frente al poder se desarrollan. El concepto de cultura política, "fue acuñado por la ciencia política norteamericana a mediados de los años cincuenta del presente siglo, en cierta medida como

\footnotetext{
35 Weber, Max, Economía y sociedad, México, Fondo de Cultura Económica, 1964, p. 696

${ }^{36}$ Rousseau, Jean Jacques, El contrato social o principios de derecho político, España, Tecnos, 2007
}

Revista de Direito da Cidade, vol.07, no01. ISSN 2317-7721 p.275-302 291 
alternativa al concepto de ideología dominante de la escuela marxista, y por lo tanto a su enfoque particular sobre la incidencia de las creencias, referentes simbólicos y actitudes sobre la Política" ${ }^{37}$.

La cultura y la política, tienen estrecha relación con los comportamientos humanos, por ello la "importancia teórica radica en que permite penetrar en los supuestos fundamentales que gobiernan las conductas políticas". "La cultura política es el patrón que surge de la distribución social de las visiones y orientaciones sobre la política y que se manifiesta exteriormente en las conductas o comportamientos políticos" ${ }^{\prime \prime 2}$.

La cultura política, nos va a permitir entender como se comporta la gente frente al poder, y como asume su responsabilidad en el ejercicio del mismo. Puesto que "toda cultura política es una composición de valores y percepciones que, como tal, no abarca orientaciones de un solo tipo, sino que generalmente combina percepciones y convicciones democráticas y/o modernas con patrones de comportamiento más o menos autoritarios y/o tradicionales" 39 .

Éste cúmulo de valores y percepciones, abona en la construcción de regímenes democráticos, pues mientras más arraigados estén esos valores, la población sentirá un compromiso consigo misma para lograr un ejercicio responsable del poder, no sólo por parte de quienes jurídicamente lo ejercen, sino de ellos como detentadores del poder político originario.

De acuerdo con Peschard, existen dos procedimientos que nos permiten identificar las propiedades de la cultura política, y estos son:

1. A partir de las condiciones sociales y económicas, así como de las instituciones políticas existentes en una sociedad democrática; $y$

2. A partir de las actitudes que se presentan en dichos sistemas democráticos ${ }^{40}$.

En este sentido, las condiciones sociales y económicas de un país, permitirán identificar de qué tipo de régimen se trata, si es una democracia, un estado totalitario o absolutista y la forma en que el poder se desenvuelve en cada uno.

La cultura política, puede presentar tres tipos de orientaciones que permiten identificar las relaciones políticas internas con los actores, instituciones y procedimientos políticos. Estas tres orientaciones son cognoscitiva, afectiva y evaluativa, es decir los actores involucrados en ella,

\footnotetext{
${ }^{37}$ Peschard, Jacqueline, op. cit., p. 13

38 Ibídem., p. 19

39 Ídem.

40 Ídem.
}

Revista de Direito da Cidade, vol.07, no01. ISSN 2317-7721 p.275-302 292 
deben tener conocimientos y contenidos sobre el sistema político y los roles que en el desempeñan, así mismo que sentimientos les genera dicho sistema, si hay aceptación o rechazo al mismo, y evaluar cuál ha sido el funcionamiento y los resultados de ese sistema político. Por ello podemos afirmar, que la cultura política se construye con conocimientos, sentimientos y un sentido crítico, lo que puede dar al sistema político una orientación de como es percibido por el total de la población.

Lo anterior obliga a señalar dos objetos políticos: uno, para el sistema político en general o en sus distintos componentes; y dos, uno mismo en cuanto actor político básico ${ }^{41}$. Los objetos políticos, apuntan directamente a la población, pues es actor político por si mismo, y a partir de ella se conforman las instituciones encargadas de ejercer jurídicamente el poder.

Las orientaciones de los sujetos políticos, permiten crear sistemas de gobierno democráticos actuales y que atiendan los problemas reales de la sociedad, pues entre más conocimiento se tenga de los fenómenos políticos mayor será el grado de crítica constructiva que la población tendrá respecto al ejercicio del poder y los sentimientos y apegos a las formas de ejercicio del poder serán de mayor trascendencia.

Cuando la cultura política contribuye en la identificación de los problemas sociales, conjunta a la sociedad y al deseo de ayudar a superar situaciones adversas. Es decir, si la población se mantiene consiente de los problemas que le afectan a cada parte del territorio, los impulsa a conocer mejor a los encargados del ejercicio del poder y a racionalizar la toma de decisiones al interior de los regímenes democráticos, además de motivar la conformación de organizaciones sociales para coadyuvar en la solución y atención de los problemas sociales que aquejan a la misma sociedad de la que provienen.

La cultura política permite a cada individuo sentirse parte del ejercicio del poder político, en sus diversos momentos, ya sea como depositario o depositante del ejercicio de esta potestad, ya sea como votante, elector, representante político y como beneficiario del ejercicio del poder.

Los componentes de la cultura política democrática, garantizan la participación de diversos sectores en el ejercicio del poder, despiertan el interés de la sociedad por los procesos del poder y de la toma de decisiones del poder público.

\footnotetext{
${ }^{41}$ Ídem.
} 
Para lograr fortalecer la cultura política y el interés de la sociedad por los procesos del poder, se requiere de un amplío camino hacia "el aprendizaje e interiorización de valores, símbolos y actitudes frente a la política, de larga duración y mucho menos directo, formal y cognoscitivo que el aprendizaje escolar. Se trata de un proceso eminentemente cultural en la medida en que intenta insertar al individuo en su sociedad al hacerlo partícipe del código de valores y actitudes que en ella son dominantes" 42

Este proceso de socialización, permite la unión entre las concepciones políticas de la población y las normas jurídicas que hacen posible la existencia del sistema político democrático. Pues fomenta el reconocimiento y aceptación de los ciudadanos en relación al sistema político y a la estructura normativa de una sociedad.

La función socializadora esta a cargo de instituciones u órganos, pudiendo adoptar, una forma directa mediante comunicación expresa de valores y sentimientos que permitan entender la importancia de la existencia del sistema político, así como el papel que los gobernados tienen en el mismo; la otra forma, es la latente o indirecta, la cual no implica únicamente la transmisión de contenidos políticos, sino más bien, la transmisión de conductas políticas a cargo de la familia, la escuela, los lugares de trabajo, los amigos, los vecinos, los grupos de intereses similares ${ }^{43}$.

Este proceso de socialización política, puede estar a cargo del mismo Estado, o de la población. Donde ésta última es refuerzo de la primera, pues los núcleos familiares y de amigos coadayuvan a la conformación de la personalidad del individuo, a su carácter y a las formas en que aprende su realidad, y la segunda se realiza fuera de las relaciones afectivas, pues se realiza a través de medios de comunicación masiva, instituciones propiamente creadas para concientización política del individuo, como asociaciones políticas, grupos políticos, entre otros.

En México el sistema democrático esta en riesgo, no sólo por la baja eficiencia en el desempeño de las funciones públicas, sino por que la gente misma ha perdido interés en relacionarse con su contexto político y de ejercicio del poder.

De acuerdo con datos de 2011 de Latinobarometro, al 36.3\% de la población en México le da igual si vive o no bajo un régimen democrático, y sólo el 39.6\% señala que es preferible una democracia a cualquier otro régimen de gobierno, la diferencia porcentual entre las dos cifras, es realmente mínima; no obstante refleja la escasa importancia que la gente demuestra por el

\footnotetext{
42 Peschard, Jacqueline, op. cit., p. 42

43 ídem.
}

Revista de Direito da Cidade, vol.07, no01. ISSN 2317-7721 p.275-302 294 
régimen de gobierno en el que se desarrolla así como por las decisiones que en su nombre y representación se toman ${ }^{44}$.

Además la sociedad mexicana, se siente poco o nada satisfecha con la forma de democracia adoptada en el país, e incluso considera que la democracia en vez de conformarse como una opción de mejora constante de la forma de vida, tal como lo establece el artículo tercero de la Constitución Política de los Estados Unidos Mexicanos, ofrece una situación de ir empeorando y presentar problemas más que soluciones a las condiciones de vida diaria.

Lo que genera desagrado por las políticas del gobierno como los intentos de reelección, o la poca confianza que la población tiene respecto del gobierno que ella misma eligió.

La última afirmación nos permite entender que la población tiene carencias en la conformación de la cultura política democrática al interior del país, pues muestra inconformidades en la forma en que se desenvuelve el ejercicio del poder por los representantes por los cuales emitió un voto.

La cultura política y cívica, deben reestructurarse en México, para poder concientizar a la población en la toma de sus decisiones en torno a las cuestiones políticas del país.

\section{Derechos humanos y su importancia en la calidad de la democracia}

Hemos atendido a la parte relacionada con el poder y su ejercicio como parte de la democracia, donde el individuo a través de la cultura política auto y heterogenerada, encuentre un espacio pleno para su desarrollo personal y laboral o profesional. En este sentido, es necesaria la concientización sobre la importancia y alcance de los derechos humanos en México, como parte del sentido humano y social de la democracia en el siglo XXI.

Los derechos esenciales de los hombres han recibido múltiples denominaciones, es decir, para hacer referencia a ellos se les han atribuido nombres, con los que tratan de caracterizar o de distinguir a los derechos fundamentales de cualquier otro tipo de derechos. Así tenemos, principalmente, a los derechos humanos y a los derechos fundamentales.

La distinción surge del ámbito significativo que abarca cada denominación, de acuerdo con Escalona, los derechos fundamentales parecen ser concretos y específicos, pues se pueden

44 Latinobarómetro, Estudio no LAT-2011, México, Latinobarómetro, 2011, disponible en: http://www.latinobarometro.org/latCodebooks.jsp

Revista de Direito da Cidade, vol.07, no01. ISSN 2317-7721 p.275-302 295 
incorporar a textos normativos y pertenecer al sistema jurídico de un país, mientras que los derechos humanos son prácticamente infinitos. En este sentido, el referido autor sostiene:

Es posible enumerar los derechos fundamentales de los que disponen los ciudadanos sujetos a un determinado ordenamiento jurídico; por el contrario, no es posible elaborar un catálogo completo de los derechos humanos de aceptación universal, ya que tal catálogo sería para algunos demasiado escasos y para otros demasiado extenso ${ }^{45}$.

Derivado de los principios de los derechos humanos, que son universales coincide con la multiplicidad que de ellos haya, pues atienden a características sociales, culturales, y políticas de cada región, además de que algunos podrán coincidir, como el derecho a la vida, a la libertad, a la salud, a la educación entre otros, sin embargo las formas que se pueden encontrar para garantizarlos dependen de las condiciones políticas de cada país. Pues algunos encontrarán medios jurisdiccionales y otros medios políticos para hacer efectivos estos derechos. Mientras que los derechos fundamentales, no quedan a la elección del gobierno y de sus legisladores, sobre que tipo de protección se les brinda, el Estado debe garantizar su cumplimiento, respeto y observancia.

En relación a lo anterior, Martínez, identifica las diferencias existentes entre derechos humanos y derechos fundamentales. Para este autor,

Los Derechos Humanos aparecen recogidos en los textos internacionales y los Derechos Fundamentales en las Constituciones nacionales. Por ello, los Derechos Humanos son universales y generales, inviolables, imprescriptibles e inalienables, pero carecen de un sistema de garantías y de medios para su realización, mientras que los derechos fundamentales son relativos y contingentes, pero gozando la tutela reforzada de los aparatos y órganos del Estado, por ello, a la vista de estas consideraciones, la expresión <<derechos fundamentales〉> se muestra como una noción <<jurídica>> apropiada en todo caso para una teoría del Derecho, mientras que la expresión $<<$ Derechos Humanos $>>$ denota una acepción lata que entorpece su uso ${ }^{46}$.

Para sintetizar la información anterior, presentamos el siguiente esquema:

\footnotetext{
45 Escalona Martínez, Gaspar, "La naturaleza de los derechos humanos", Pasado, Presente y Futuro de los derechos humanos, México, Comisión Nacional de Derechos Humanos, Universidad Nacional de Educación a Distancia, 2004, pp. 154-157

${ }^{46}$ Martínez De Pisón, José, Tolerancia y derechos fundamentales en las sociedades multiculturales, España, Tecnos, 2001, p. 168
}

Revista de Direito da Cidade, vol.07, no01. ISSN 2317-7721 p.275-302 296 


\begin{tabular}{|c|c|}
\hline DERECHOS HUMANOS & DERECHOS FUNDAMENTALES \\
\hline Contenidos en tratados internacionales & Contenidos en las Constituciones Políticas \\
\hline $\begin{array}{c}\text { Principios: universales, generales, } \\
\text { imprescriptibles, e inalienables }\end{array}$ & Principios: relativos, contingentes, positivados \\
\hline $\begin{array}{c}\text { Carecen de un sistema de garantías procesales } \\
\text { o constitucionales }\end{array}$ & $\begin{array}{c}\text { Gozan de una tutela reforzada de los aparatos y } \\
\text { órganos del Estado }\end{array}$ \\
\hline \multicolumn{2}{|c|}{ Noción iusnaturalista } \\
\hline \multicolumn{2}{|c|}{ Nuente. Elaboración jurídica positiva } \\
\hline
\end{tabular}

En este sentido, Peces Barba, quién considera que los derechos fundamentales son una terminología adecuada para nombrar a las prerrogativas de las que goza el ciudadano o habitante de cualquier país, pues se refieren a:

1. Es un término más preciso que la expresión derechos humanos y evita sus ambigüedades;

2. Abarca la dimensión jurídica y moral de los derechos superando la confrontación entre iusnaturalismo y positivismo;

3. Es más adecuado que los términos "derechos naturales", "derechos morales", que mutilan a los derechos humanos de su faceta jurídico positiva, dicho de otra forma, que formulan su concepto sin tener en cuenta su dimensión jurídico positiva;

4. Es más adecuado que el resto de términos que olvidan su dimensión moral ${ }^{47}$.

Al estar contenidos en una Constitución, podría resultar más efectiva su protección y respeto, pues recordemos que la Constitución es, en palabras de Kelsen, la norma fundante básica de los sistemas jurídicos de cualquier país, y con ello, el sistema jurídico da fundamento a la organización del Estado, quien valida las instituciones que han de prestar especial cuidado en la protección y defensa de los derechos fundamentales a través de los organismos y procesos correspondientes, por lo que estos derechos fundamentales se convierten en un límite para el ejercicio del poder.

Por su parte, Pérez sostiene la separación entre estos dos términos, en virtud de que no significan lo mismo, pues los derechos humanos reflejan la aspiración del ser humano, mientras que los derechos fundamentales poseen una dimensión ontológica, al ser los derechos que fundan el ordenamiento jurídico, en este sentido:

\footnotetext{
${ }^{47}$ Ibídem, p. 173
}

Revista de Direito da Cidade, vol.07, no01. ISSN 2317-7721 p.275-302 297 
Se trata de aquellas facultades inherentes a la persona que deben ser reconocidas por el derecho positivo. Cuando se produce ese reconocimiento aparecen los derechos fundamentales, cuyo nombre evoca su función fundamentadora del orden jurídico de los Estados de derecho. Por tanto, los derechos fundamentales constituyen un sector, sin duda el más importante, de los ordenamientos jurídicos positivos democráticos ${ }^{48}$.

Sin embargo, estas diferencias pueden ser difuminadas con un nuevo término, que reconoce a los derechos en su dimensión jurídico-moral-iusnaturalista, ésta denominación es derechos constitucionales, que pueden ser entendidos como "aquellas concretas expresiones de la dignidad, libertad e igualdad humanas dispuestas jurídicamente, que han sido recogidas -expresa o implícitamente- en la norma constitucional, y que vinculan positiva o negativamente al poder político al punto de legitimar su existencia y actuación”49.

Para Luis Castillo, los derechos constitucionales, son "manifestaciones de valores y principios jurídicos que vienen exigidos necesariamente por la naturaleza humana: dignidad humana, libertad e igualdad. Son valores o principios jurídicos que no tienen su existencia limitada al campo moral axiológico, sino trascienden de él y se instalan en el ámbito de lo jurídico de modo que la sola existencia del hombre hace que sea exigible su reconocimiento y consecuente tratamiento como ser digno, libre e igual que es" ${ }^{\prime 50}$.

Las denominaciones dadas a los derechos esenciales del ser humano, no pueden ser llamados de una forma única o exclusiva, sino que depende del documento o momento de su utilización. Es decir el término "derechos humanos" es utilizado en el ámbito internacional y carecen de los medios procesales para hacerlos valer; los "derechos fundamentales" han sido incorporados al texto constitucional de un país y gozan de una protección jurisdiccional que permite en algunos casos la reparación tratándose de una violación, a pesar de ello, no se puede concluir que los derechos fundamentales abarcan a la totalidad de los derechos humanos. Por otro lado el término "derechos constitucionales" pareciera ser el más indicado al situarse en el ámbito jurídico exclusivamente, sin embargo no hay garantía alguna de que la totalidad de los derechos

\footnotetext{
${ }^{48}$ Aguilar Cavallo, Gonzalo, "Derechos fundamentales-Derechos humanos. ¿Una distinción válida en el siglo XXI?", Boletín Mexicano de Derecho Comparado, México, UNAM, 2010, nueva serie, año XLII, núm. 127, enero-abril, pp. 23 y 24

${ }^{49}$ Castillo Córdova, Luis, Los derechos constitucionales. Elementos para una teoría general, 3a. ed., Perú, Palestra, 2007, pp. 208-209

${ }^{50}$ Idem.
}

Revista de Direito da Cidade, vol.07, no.01. ISSN 2317-7721 p.275-302 298 
fundamentales estén incorporados al texto constitucional. Sino que todo depende del constituyente que al momento de crear la Constitución, es quien decide que derechos incorpora y que derechos considera no fundamentales para los naturales de su país.

Es preciso anotar, que después de la reforma de 2011 en México a la Constitución federal, en donde se reconocen los derechos humanos en el artículo primero, las diferencias entre las denominaciones se van haciendo más tenues, pues con ella se eleva a rango constitucional los derechos humanos contenidos en los diversos tratados internacionales.

Con este reconocimiento a los derechos humanos en el contexto mexicano, en donde los tratados internacionales debe adquirir plena vigencia y aplicabilidad, todos los derechos en ellos contenidos serán tomados en cuenta en nuestro país, al ser México uno de los países firmantes.

De este modo recordemos el Pacto Internacional de Derechos Civiles y Políticos, el cual determina obligaciones para los Estados Parte, enuncia los derechos humanos mínimos que deben ser reconocidos, respetados y potenciados por los países, y entre ellos encontramos a los civiles y políticos, debiendo desarrollarse en una sociedad democrática.

Este instrumento internacional, no sólo nos permite hablar de derechos humanos, ni de derechos y obligaciones recíprocos, sino de un régimen político que debe garantizar estos elementos.

Este instrumento patentiza los derechos a a) participar en la dirección de los asuntos públicos, directamente o por medio de representantes libremente elegidos; b) Votar y ser elegidos en elecciones periódicas, auténticas, realizadas por sufragio universal e igual y por voto secreto que garantice la libre expresión de la voluntad de los electores; c) Tener acceso, en condiciones generales de igualdad, a las funciones públicas de su país ${ }^{51}$.

En este sentido, los Estados deben generar programas y acciones que permitan a sus habitantes comprender y participar activamente en los procesos políticos del país.

\footnotetext{
51 Organización de las Naciones Unidas, Pacto Internacional de Derechos Civiles y Políticos, disponible en: http://www2.ohchr.org/spanish/law/ccpr.htm
}

Revista de Direito da Cidade, vol.07, n0.01. ISSN 2317-7721 p.275-302 299 


\section{REFLEXIONES FINALES}

México afronta retos ante la modernidad, y en la consolidación de un sistema democrático. Educación, salud, empleo, respeto a los derechos humanos, son algunos de los problemas que deben ser atendidos por el Estado de manera inmediata.

Se entiende grave la percepción de los habitantes en relación al funcionamiento de la administración pública, a los grandes problemas de corrupción, los desvíos de recursos federales hacia las cuentas personales de los servidores públicos, los niveles de enseñanza en el sector educativo son bajos, la calidad de los maestros en la enseñanza requiere de atención urgente, instalaciones para el desarrollo de las actividades escolares, atención a la salud, trabajos con una remuneración que realmente permita la adquisición de productos de primera necesidad, además de que permita la distracción y el entretenimiento.

Son cuestiones que el gobierno y la población de México deben atender, para poder incrementar la calidad de vida y desarrollo.

Nuestro país y la sociedad mexicana deben participar de forma conjunta en el entendimiento de los procesos políticos en los que están inmersos, de forma directa o indirecta. Como Estado, México puede replantear las políticas públicas tomando como referencia a la persona, no al individuo, es decir que en acciones positivas del gobierno, se promueva la conciencia como parte activa de un proceso político cambiante y que difícilmente será el mismo, como sociedad, nos corresponde fomentar y fortalecer la responsabilidad política y social de los individuos, entender que no sólo el gobierno es quien decide o quien puede gastar el dinero, no es sólo el gobierno o el grupo en el poder quien determina las directrices del país.

México debe evolucionar de una democracia electoral y de partidos, a una democracia social, en donde se haga uso de la cultura política, donde la sociedad constantemente cuestione las acciones del gobierno, supervise la actuación gubernamental, donde el Estado este al servicio del ciudadano y del habitante.

Sólo si los habitantes ponen interés en las cuestiones del poder, será posible construir una democracia social incluyente y fortalecida. Pues solo la cultura y la acción nos separan de las potencias mundiales. 


\section{FUENTES DE CONSULTA}

AGUILAR CAVALLO, Gonzalo, Derechos fundamentales-Derechos humanos. ¿Una distinción válida en el siglo XXI?, Boletín Mexicano de Derecho Comparado, México, UNAM, 2010, nueva serie, año XLII, núm. 127, enero-abril

CARPIZO, Jorge, Concepto de democracia y sistema de gobierno en América Latina, Boletín Mexicano de Derecho Comparado, México, Universidad Nacional Autónoma de México, 2007, número 119 Castillo Córdova, Luis, Los derechos constitucionales. Elementos para una teoría general, 3ą. ed., Perú, Palestra, 2007

COVIÁN ANDRADE, Miguel, Retos del sistema electoral y de la democracia mexicana en el siglo XXI, México, Cámara de Diputados, disponible en: www.diputados.gob.mx/documentos/consejeros_2013/ensayo/30.pdf, consultado: 18/02/2014g

DWORKIN, Ronald, La democracia posible. Principios para un nuevo debate político, España, Paidós, 2008

ESCALONA MARTÍNEZ, Gaspar, La naturaleza de los derechos humanos, Pasado, Presente y Futuro de los derechos humanos, México, Comisión Nacional de Derechos Humanos, Universidad Nacional de Educación a Distancia, 2004

FUENTES GARCíA, Alejandra, ¿Cómo el Ingreso Afecta la Salud?: La Perspectiva de la Epidemiología Social, Revista Ciencia \& Trabajo, Chile, 2010, año 12, número 35

LATINOBARÓMETRO, Estudio, no LAT-2011, México, Latinobarómetro, 2011, disponible en: http://www.latinobarometro.org/latCodebooks.jsp

LIZCANO FERNÁNDEZ, Francisco, et. al., Conceptos de democracia y calidad de la democracia, en , Francisco y Retana Ramírez, Ruperto (coords.), Estado de México y democracia en los albores del siglo XXI, México, 2010

MARTÍNEZ DE PISÓN, José, Tolerancia y derechos fundamentales en las sociedades multiculturales, España, Tecnos, 2001

NORRIS, Pipa, La participación ciudadana: México desde una perspectiva comparativa, Deconstruyendo la ciudadanía: Avances y retos en el desarrollo de la cultura democrática en México, México, Instituto Federal Electoral, 2002

O' DONNELL, Guillermo, Democracia, Desarrollo humano y Derechos humanos, Democracia, desarrollo humano y ciudadanía. Reflexiones sobre la calidad de la democracia en América Latina, Argentina, Homo Sapiens ediciones, 2003

ORGANIZACIÓN DE LAS NACIONES UNIDAS, Pacto Internacional de Derechos Civiles y Políticos, disponible en: http://www2.ohchr.org/spanish/law/ccpr.htm

Revista de Direito da Cidade, vol.07, no01. ISSN 2317-7721 p.275-302 301 
Promoción del derecho a la democracia, Resolución de la Comisión de Derechos Humanos 1999/57, 1999, disponible en: www.unhchr.ch/huridocda/huridoca.nsf/8ce8951852ee031cc1256991003793c3/d5d1445feb8c7e3 c8025676e003b4495?OpenDocument

ORGANIZACIÓN DE LAS NACIONES UNIDAS PARA LA EDUCACIÓN, LA CIENCIA Y LA CULTURA (UNESCO), web site: http://www.unesco.org/new/es/mexico/work-areas/culture/

ORGANIZACIÓN PARA LA COOPERACIÓN Y DESARROLLO ECONÓMICOS, México a detalle, Índice de Vida Mejor, disponible en: http://www.oecdbetterlifeindex.org/es/countries/mexico-es/

PESCHARD, Jacqueline, La cultura política democrática, Cuadernos de Divulgación de la Cultura Democrática, México, Instituto Federal Electoral, disponible en: http://biblio.juridicas.unam.mx/libros/libro.htm?l=497

PROGRAMA DE LAS NACIONES UNIDAS PARA EL DESARROLLO, Informe Anual 2012, Desarrollo centrado en las personas, PNUD, 2012

Informe sobre Desarrollo Humano, México, PNUD, 2011

Nuestra democracia, PNUD, México, FCE, PNUD, OEA, 2010

ROUSSEAU, Jean Jacques, El contrato social o principios de derecho político, España, Tecnos, 2007

VALADÉS, Diego, El control del poder, México, UNAM, 1998

WEBER, Max, Economía y sociedad, México, Fondo de Cultura Económica, 1964

WORLD HAPPINESS REPORT 2013, disponible en:

http://unsdsn.org/files/2013/09/WorldHappinessReport2013_online.pdf

Trabalho enviado em 06 de outubro de 2014.

Aceito em 19 de dezembro de 2014.

Revista de Direito da Cidade, vol.07, no⒈ ISSN 2317-7721 p.275-302 302 